\title{
Screening of metal-resistant coal mine bacteria for biofabrication of elemental silver nanoparticle
}

\author{
SUBHASMITA PANDA, KANTI KUSUM YADAV, PARTH SARTHI NAYAK, \\ MANORANJAN ARAKHA* and SUMAN JHA \\ Department of Life Science, National Institute of Technology Rourkela, Odisha 769008, India
}

MS received 21 July 2015; accepted 17 November 2015

\begin{abstract}
Green synthesis approaches for nanoparticle synthesis are considered as nontoxic, eco-friendly and cost-effective approaches than other physical and chemical approaches. Here, we report green synthesis of silver nanoparticle using the bacteria from the habitat of relatively metal-rich coal mine dust. The bacteria showed resistance to significant concentration of anti-microbial $\mathrm{Ag}(\mathrm{I})$ ion. The nanoparticle was synthesized at minimum inhibitory concentration (MIC) of $\mathrm{Ag}(\mathrm{I})$ using only two isolates. The synthesis of silver nanoparticle was confirmed from the surface plasmon resonance property of the nanoparticle, whereas morphological features were studied using field emission scanning electron microscope. The hydrodynamic size analysis showed the presence of microparticles along with the nanoparticles. Additionally, IR study provided information about the bacterial proteins involved in either reduction of $\mathbf{A g}(\mathbf{I})$ into silver nanoparticle or capping of reduced silver nanocrystal or both. Thus, majority of the bacteria found in the coal mines have the resistance against the antimicrobial metal ion, and the potential to reduce the ion into nano- or micro-particles. Hence, the bacteria can be used as a single cell factory for production of silver nanomaterial.
\end{abstract}

Keywords. Green synthesis; nanoparticles; bacteria; bacterial interface; MIC.

\section{Introduction}

Nanoparticles have become very important and leading edge of the wide developing field of nanotechnology [1]. Their unique size-dependent properties and high surface to volume ratio make them superior and indispensable in many areas of technologies as well as medicines [2,3]. Additionally, nanoparticles represent an important class of materials in production and development of novel devices those can be used in various biological, physical, pharmaceutical and biomedical applications [4]. Hence, there is a great interest in the synthesis of nanoparticles due to their unique and unusual optical [5], chemical [6], photo-electrochemical [7] and electronic [8] properties. Additionally, some of the other sizedependant properties of nanoparticles include surface plasmon resonance, quantum confinement in semiconductors [9] and superparamagnetism in magnetic materials [10]. Hence, the metallic nanoparticles have found many applications in diverse areas such as optics, electronics, coatings, cosmetics, packaging and biotechnology. Noble metals, especially gold and silver nanoparticles exhibit some unique and tunable optical properties due to their surface plasmon resonance property [11,12]. Different chemical and physical procedures are used for synthesis of metallic nanoparticles. However, these methods face some major limitations in terms of toxic chemicals use, generation of hazardous by-products and high energy consumption [13]. Accordingly, there is

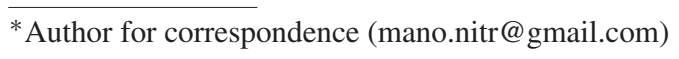

tremendous need to develop high yield, low cost, nontoxic and environment-friendly procedures for synthesis of metallic nanoparticles. Green nanotechnology not only encourages fundamental but also goal-oriented research in both the academic and industrial fields for the design and development of nanoparticles. These nanoparticles have already been used in the design of smart electronic devices, life-saving nanopharmaceuticals and green energy production devices, as well. Synthesis of nanoscale material using biological systems is relatively clean, cost effective, easily scaled up for large scale synthesis, nontoxic and eco-friendly procedure, compared to conventional synthesis techniques. Hence, green synthesis methods are gaining importance [14].

A number of biological resources available in nature including plants, plant products, algae, bacteria and fungi can be used for the synthesis of nanoparticles. Among the microorganisms, bacteria have received the most attention in the area of biosynthesis of nanoparticles due to their resistance against different heavy metals [15]. The ability of bacteria to grow in presence of high metal ion concentrations is linked to different surviving skills adopted by the bacteria, for example, efflux systems, alteration of solubility and toxicity by changing the respective metal redox state (nontoxic state), extracellular complexation or precipitation of metals and specific metal transport systems. In short, bacteria have relatively very high adoptability among microorganisms $[16,17]$. It is already known that silver is highly toxic to most of the microbial cells. Hence, selection of heavy metalresistant bacterial strains is a key issue for the synthesis of 
silver nanoparticles. Thus, produced AgNPs can be used extensively as an anti-bacterial agents in health and textile industries, for food storage and number of other environmental anti-bacterial applications $[18,19]$.

Based on these concepts, we have extended our study on the green synthesis of silver nano/microparticles using metaltolerating bacteria from coal dust. For the same, we have chosen coal mine as a place to isolate bacteria. Due to high temperature, low $\mathrm{pH}$ and high metal ions content, coal mine soil is treated as physico-chemically stressful habitat for soil microorganisms $[20,21]$. Thus, the coal mine is the habitat for bacteria which can withstand high concentration of silver metal ions and adverse physico-chemical conditions like change in $\mathrm{pH}$ and temperature during the synthesis of nano/microparticles at industrial scale. We have isolated bacterial strains from coal mine and evaluated their metal tolerance capacity against $\mathrm{AgNO}_{3}$, and used the metal-resistant bacteria for successful reduction of silver ion into silver nano- and micro-particles.

\section{Materials and methods}

Nutrient broth and nutrient agar were purchased from Himedia, India. Silver nitrate $\left(\mathrm{AgNO}_{3}\right)$ was purchased from Sigma-Aldrich (Germany). The bacteria used for synthesis of silver nanoparticles were isolated from the coal dust samples collected from the Sambleshwari open crust project, Lajkura, Jharsuguda, Odisha, India. For experimental purpose, the coal dust samples were collected from the coal mine using sterile vials.

\subsection{Isolation of bacterial samples}

For isolation of bacterial strains, $100 \mathrm{mg}$ coal powder was measured and dissolved in $1 \mathrm{ml}$ of autoclaved distilled water, followed by 10000 times dilution using autoclaved distilled water. Twenty microlitres of the solution was spread on agar plate and kept for overnight incubation at $37^{\circ} \mathrm{C}$. The slant cultures of bacterial strains were prepared for further use by taking single colonies from the plates. We have isolated many strains and randomly chosen three among them for further experimental works.

\subsection{Determination of $\mathrm{AgNO}_{3}$ minimum inhibitory concentration against extracted bacteria}

Minimum inhibitory concentration (MIC) was determined to check resistance of extracted bacteria against silver metal ions in comparison with normal chemical conditions. The mother cultures of the bacteria were prepared by inoculating a loop full of bacteria into $5 \mathrm{ml}$ nutrient broth, and incubated overnight at $150 \mathrm{rpm}$ and $37^{\circ} \mathrm{C}$. Different reaction mixtures were prepared in 96 well plates, taking different concentrations $(0,0.019,0.15$ and $1.25 \mathrm{mM})$ of $\mathrm{AgNO}_{3}$ and $20 \mu \mathrm{l}$ of bacterial culture. The reaction volume was adjusted to final volume of $300 \mu \mathrm{l}$ using nutrient broth. The growth of bacteria was observed by studying time dependent change in O.D. at $600 \mathrm{~nm}$ when bacteria were incubated at $37^{\circ} \mathrm{C}$ using micro-plate reader (Synergy H1, Biotek, Singapore). Colony forming unit (CFU) measurements were performed to estimate the number of viable bacteria cells present in different reaction mixtures. The samples were taken from early stationary phase of the respective growth curve, i.e. bacteria grown in presence of $0,0.019,0.15$ and $1.25 \mathrm{mM} \mathrm{AgNO}_{3}$. The samples were spread on nutrient agar plate after 10000 times dilution. The plates were kept overnight in incubator at $37^{\circ} \mathrm{C}$ for their discrete colony formation, and the colonies were counted and expressed as percentage of viable cells. The percentage of viability was measured by comparing the number of colonies obtained in the presence $v s$. the absence of $\mathrm{AgNO}_{3}$ in culture medium. Additionally, we characterized the three bacteria using the standard protocol of Gram staining to know whether the bacteria are Gram positive or Gram negative. The measurement showed that the two bacteria resistant to $\mathrm{AgNO}_{3}$ were Gram positive, and the bacteria sensitive to $\mathrm{AgNO}_{3}$ was Gram negative bacteria. Thus, we selected two resistant bacteria for synthesis of AgNP.

\subsection{Synthesis of silver nanoparticles (AgNPs)}

For synthesis of AgNP, $5 \mathrm{ml}$ mother cultures of two bacteria were prepared in nutrient broth, and kept overnight at $37^{\circ} \mathrm{C}$ and $150 \mathrm{rpm}$. One millilitre of the culture was added to $100 \mathrm{ml}$ of nutrient broth, and left for growth at $37^{\circ} \mathrm{C}$ and $150 \mathrm{rpm}$ agitation. Appropriate amount of $\mathrm{AgNO}_{3}$ was added at the mid log phase of growth to obtain the MIC value $(0.15 \mathrm{mM})$ of $\mathrm{AgNO}_{3}$ in growth medium. The reaction mixtures were incubated further for $24 \mathrm{~h}$ at $37^{\circ} \mathrm{C}$ with agitation at $150 \mathrm{rpm}$ for nanoparticle synthesis. The bacterial culture containing the nanoparticle was sonicated followed by centrifugation at $6000 \mathrm{rpm}$ for $15 \mathrm{~min}$ and the supernatant was collected for characterization of AgNPs. The nanoparticle samples obtained from the two bacteria were named as AgNP1 and AgNP2, respectively.

\subsection{Characterization of silver nanoparticles (AgNPs)}

2.4a UV-Visible spectroscopic analysis of silver nanoparticles: The synthesis of silver nanoparticle (bioreduction of silver ions to silver nanoparticle) was confirmed using UVVis spectroscope (Cary 100, Agilent Technology, Singapore) within the range of 350-600 nm. Silver nanoparticle has surface plasmon resonance at a particular wavelength, i.e., $420 \mathrm{~nm}$. Hence, the spectra collected for the samples having peaks at $420 \mathrm{~nm}$ confirmed the presence of AgNP in the samples. However, the peak wavelength shifts according to the size and corona present at the nanoparticle surface.

2.4b Dynamic light scattering analysis: Dynamic light scattering is a technique to determine the size distribution of particles in aqueous solution. Here, the Zeta analyzer (Malvern Zetasizer Nano ZS90, The Netherlands) used to measure the distribution of biofabricated nanoparticles in 
aqueous solution. Additionally, stability of nanoparticles was evaluated using the Zeta analyzer by measuring zeta potential values for the samples.

2.4c Morphological study using field emission scanning electron microscope: The morphology of bacteria after treatment of $\mathrm{AgNO}_{3}$ at MIC was studied using field emission scanning electron microscope (FE-SEM, Nova Nano SEM 450, FEI, Netherlands). The samples were prepared following the protocol adopted by Arakha et al [1]. In brief, the $\mathrm{AgNO}_{3}$ treated bacterial samples were collected from the stationary phase of growth kinetics and centrifuged at $5000 \mathrm{rpm}$ for 5 min. Pellets were collected and washed twice using PBS buffer, and resuspended in PBS buffer. One drop of the resuspended bacteria sample was put on glass slide and kept for drying in incubator at $37^{\circ} \mathrm{C}$. The dried bacterial samples were flooded with glutaraldehyde $(2.5 \%)$ and kept for overnight $(\sim 18 \mathrm{~h})$ incubation at room temperature. After incubation, $1 \%$ tannic acid was flooded over the slides, and the slides were kept for $5 \mathrm{~min}$ at room temperature. The slides were again washed with distilled water, and dehydrated with different ethanol dilutions $(30,50,70,90$ and 100\%), and kept for drying. After gold coating of the samples for $3 \mathrm{~min}$, the samples were scanned for bacteria as well as nanoparticle morphology using FE-SEM.

2.4d EDX analysis of silver nanoparticles: Energy dispersive X-ray spectroscopic analysis (EDX) is an analytical tool which demonstrates the elemental composition or chemical composition of synthesized sample. Here, the elemental composition of synthesized nanoparticle samples was evaluated using the energy dispersive X-ray spectroscope attached with the FE-SEM.

\section{4e Attenuated total reflection Fourier transform infrared} spectra analysis: The samples were characterized using attenuated total reflection Fourier transform infrared (ATRFTIR) spectroscope ( $\alpha 2$ model, Bruker, Germany) to observe the bond level vibrations of different bonds present in the synthesized samples. For the measurements, samples were sonicated and analysed on the diamond platform of
ATR-FTIR with 128 scans at $8 \mathrm{~cm}^{-1}$ resolution in a range of 2000-500 $\mathrm{cm}^{-1}$.

\section{Result and discussion}

\subsection{Determination of $\mathrm{AgNO}_{3} \mathrm{MIC}$ against the extracted bacteria}

Figure 1 showed the viability of three bacteria treated with different concentrations of $\mathrm{AgNO}_{3}$. From the result, it is confirmed that $0.15 \mathrm{mM} \mathrm{AgNO}$ is the MIC for first two bacteria, whereas bacteria 3 has $\mathrm{MIC}$ at less than $0.019 \mathrm{mM}$. The bacterial growth was only $\sim 50 \%$ of the growth happening in absence of the metal ions for first two bacteria, whereas approximately $10 \%$ cells were found viable in presence of $0.15 \mathrm{mM} \mathrm{AgNO}_{3}$ for the third bacteria. Hence, we have chosen $\mathrm{MIC}$ value, $0.15 \mathrm{mM} \mathrm{AgNO}_{3}$, for the synthesis of nanoparticles using the two metal ion resistant bacteria. Bacteria 1 showed relatively higher viability at $0.15 \mathrm{mM}$ $\mathrm{AgNO}_{3}$ than bacteria 2, hence we expected relatively higher amount of reduced silver element in bacteria 1 extract. Interestingly, unlike the bacteria 3 (Gram negative), the other two $\mathrm{AgNO}_{3}$-resistant bacteria were found to be Gram positive (figure 2). The sensitivity of third bacteria towards $\mathrm{AgNO}_{3}$ can be explained by taking the surface potential of both bacteria and $\operatorname{Ag}(\mathrm{I})$ ion into consideration. Having higher surface potential than Gram positive bacteria, Gram negative bacteria easily interact with positively charged $\mathrm{Ag}(\mathrm{I})$ ion, hence the bacterial death occurs to a large extent in comparison to Gram positive bacteria. Arakha et al [1] have indicated the role of interfacial potential in inhibition of bacterial growth to different extent. Hence, Gram positive bacteria were found more resistant against $\mathrm{AgNO}_{3}$.

Although various studies have already been done to synthesize silver nanoparticles using different bacteria, but in most of the studies $\mathrm{Ag}(\mathrm{I})$ ion [22,23] are reduced to elemental silver $(\mathrm{Ag}(0))$ nanocrystals using bacterial biomass, i.e., bacterial cytoplasm. However, our study intends to synthesize the nanoparticles from live bacteria, even if the yield is relatively low. The yield of the nanoparticle can be enhanced by adopting the approach in biofermenter. Hence, MIC study was done to screen the extracted bacteria for the metal
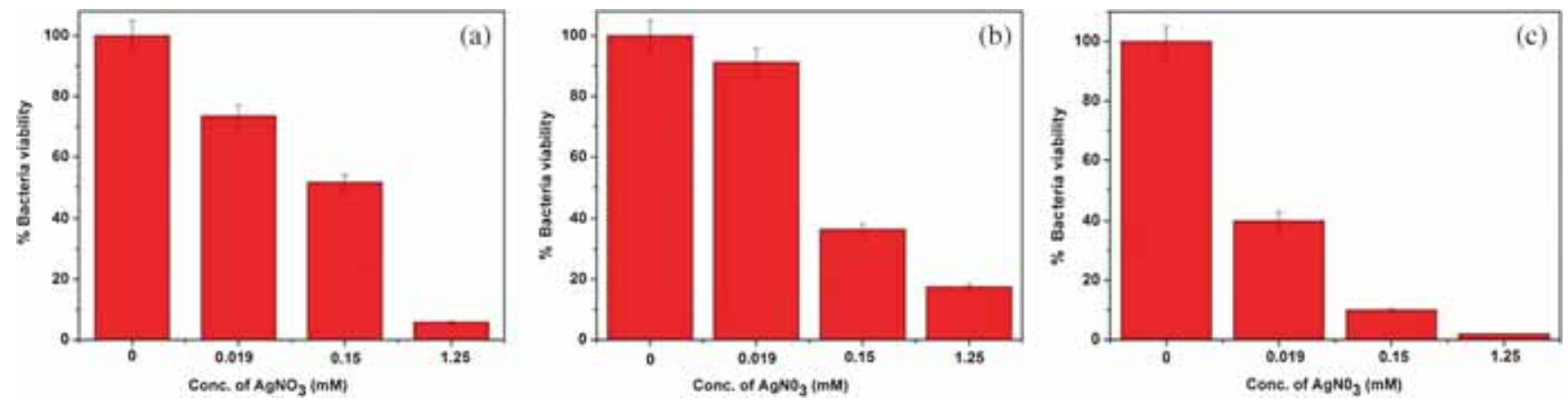

Figure 1. MIC of $\mathrm{AgNO}_{3}$ against (a) bacteria 1, (b) bacteria 2 and (c) bacteria 3 . 


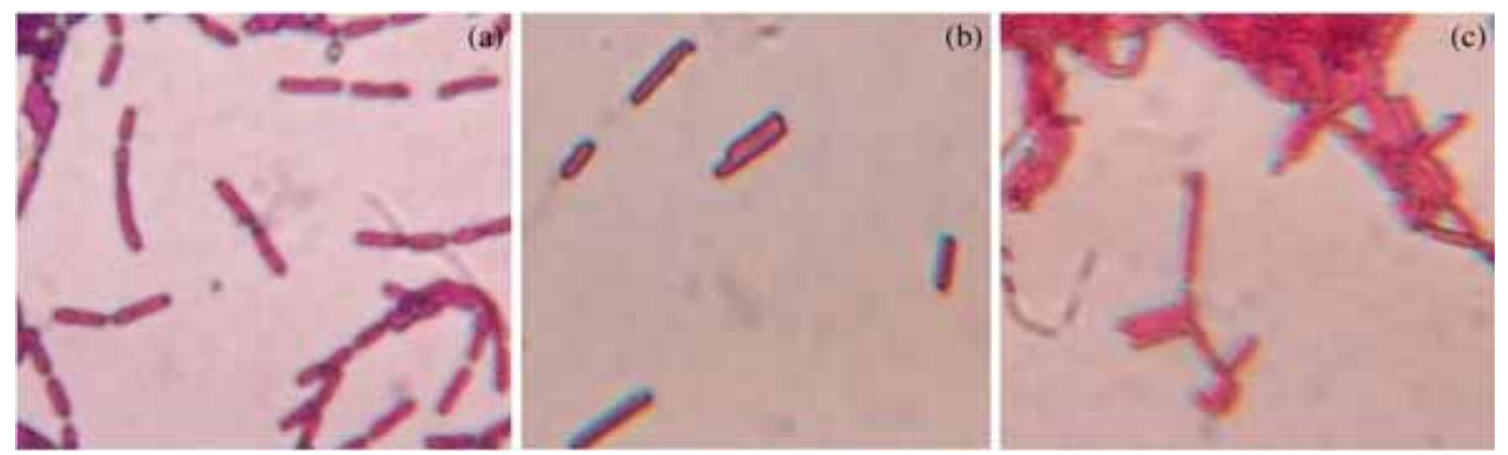

Figure 2. Characterization of bacterial strains by Gram staining and found to be (a) bacteria 1-Gram positive, (b) bacteria 2-Gram positive and (c) bacteria 3-Gram negative.

resistance. In the study, three bacteria were evaluated for their resistance against different concentrations of $\mathrm{AgNO}_{3}$, and the two metal-resistant strains found most suitable for our study. Further, $0.15 \mathrm{mM} \mathrm{AgNO}_{3}$ (MIC conc.) was added at mid $\log$ phase of the growth curve, i.e., the phase where bacteria are more potent to adopt the change in physicochemical conditions. Hence, the bacteria synthesized elemental metal nanoparticles upon internalizing and reducing the metal ions in duration of their further growth. Thus, the nanoparticles are formed during the growth of bacteria without significant change in bacterial viability. The process is named as 'online biofabrication of silver nanoparticles'. Ramanathan et al [24] have also synthesized pure copper nanoparticles using the bacteria Morganella morganii which used to be a silver-resistant strain. However, in this work, metal ion was added for reduction into elemental copper nanocrystals after the growth of the bacteria, i.e. the bacterial biomass is used to reduce the $\mathrm{Cu}$ (II) ion. Unlike Ramanathan's [24] work, we added the metal ion solution (MIC concentration) at the mid log phase of the bacterial growth, and observed the formation of micro-/nano-particles by live bacteria. Hence, the protocol can be directly adopted for online fabrication of silver nanoparticles using the extracted/metal resistant bacteria.

\subsection{UV-Visible spectroscopic analysis of nanoparticle surface plasmon resonance}

Figure 3 showed the UV-Vis spectra of silver nanoparticles synthesized using two bacteria. For both the samples, absorption peak at $425 \mathrm{~nm}$ confirmed the presence of silver nanoparticle, and the result is in accordance with the published results $[2,25]$. The strong interaction between light of particular wavelength (photons) and metal nanoparticles results in the enhanced collective oscillation of valence/ conduction electrons of the silver element present at surface of the particle, which in turn result in unusually strong absorption and scattering properties of the metal nanoparticle. The property is commonly known as surface plasmon resonance (SPR) of nanoparticle. The unique optical property (SPR) provides a great deal of information about the

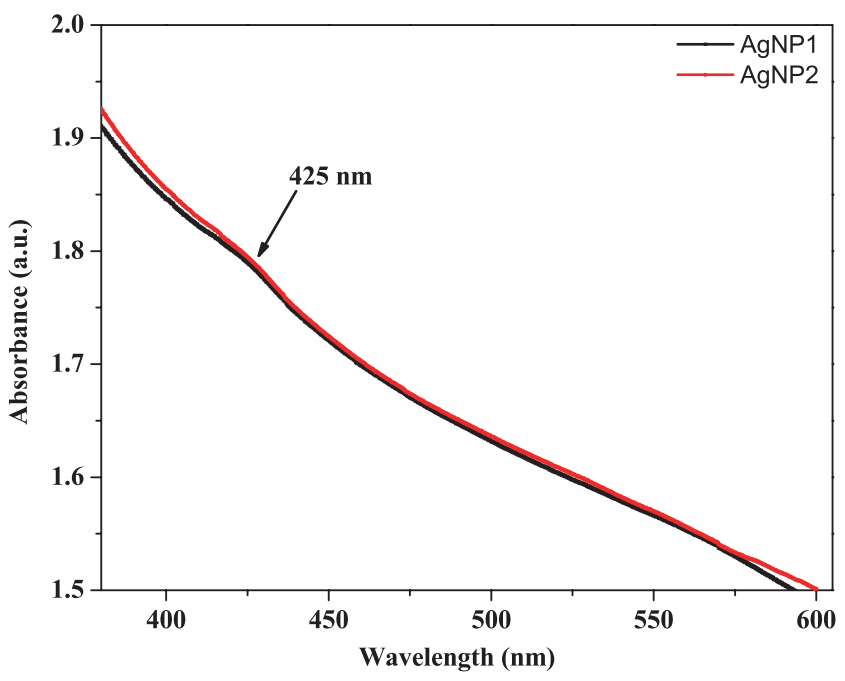

Figure 3. UV-Visible absorption spectra of AgNPs synthesized from bacteria.

physical state of silver nanoparticle [26]. The broaden peaks at $425 \mathrm{~nm}$ confirm polydispersity of the nanoparticle that means presence of some microparticles in the fabricated sample. Additionally, the intensity at $425 \mathrm{~nm}$ indicated the quantity of the particles; smaller the intensity, lower is the concentration.

\subsection{DLS analysis for size of the particles}

Zeta sizer was employed to measure the hydrodynamic size of the particles. Figure 4 showed the DLS analysis of silver nanoparticles obtained using two bacteria. As shown in the figure, the average particle size was found to be 624 and $856 \mathrm{~nm}$ for AgNP1 and AgNP2, respectively. Hence, the results indicate that some microparticles are also present in addition to the nanoparticles in our synthesized nanoparticle suspension. The observation further supports our analysis obtained from SPR spectra collected using UV-Visible spectroscope, i.e., broadening of peaks at $425 \mathrm{~nm}$ for both the samples indicating the presence of larger size nanoparticles (here, they are mentioned as microparticles). 

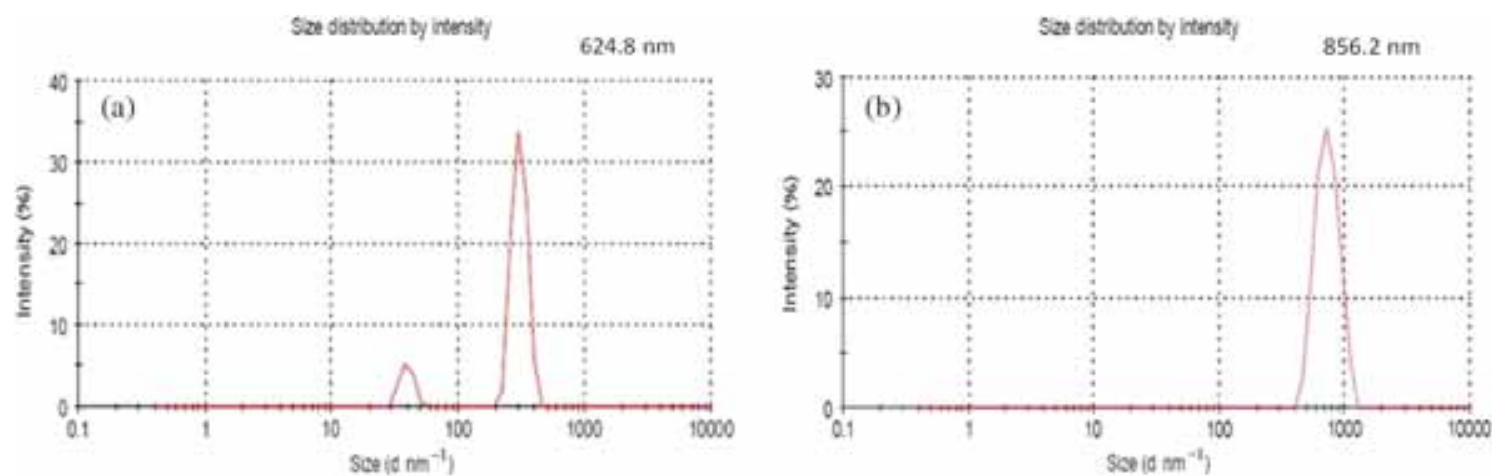

Figure 4. DLS analysis of silver nanoparticle samples: (a) AgNP1 and (b) AgNP2.
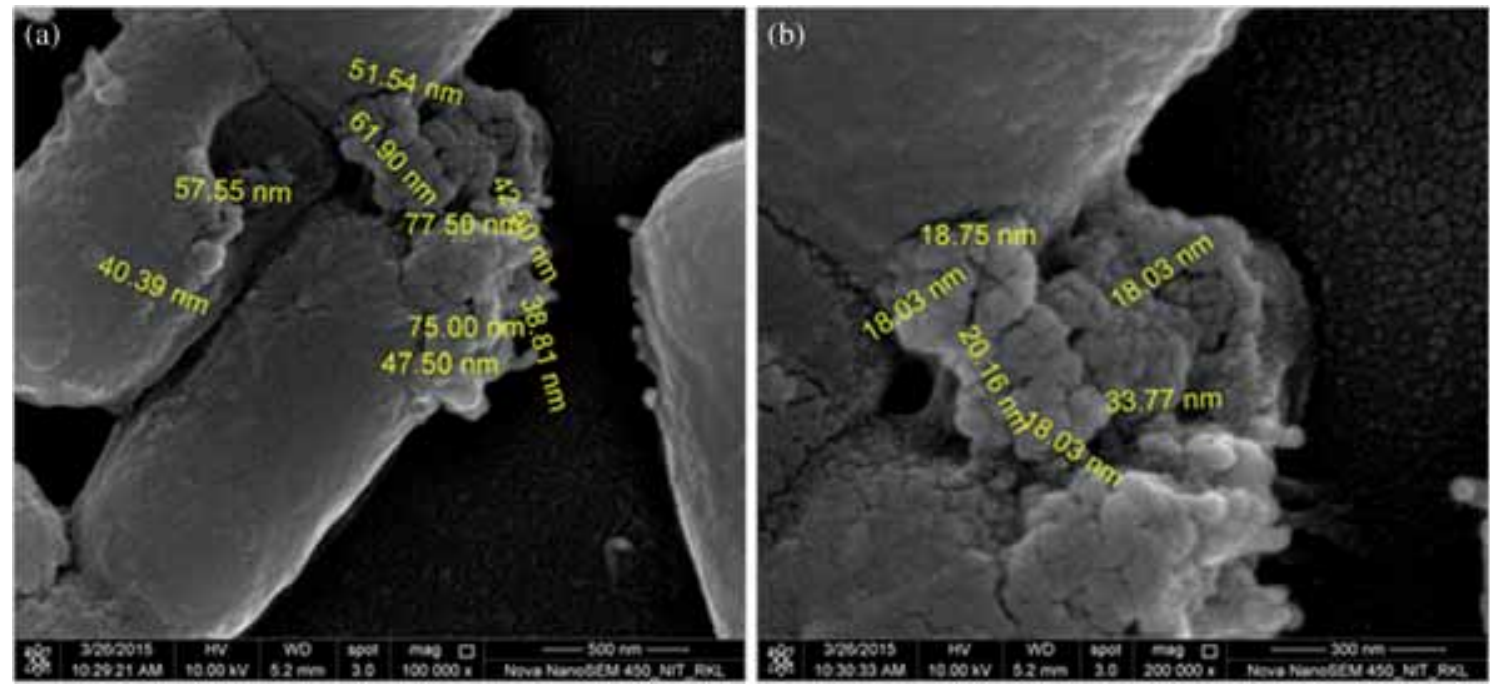

Figure 5. FE-SEM micrographs of (a) bacteria 1 with AgNP1 and (b) bacteria 2 with AgNP2 grown in presence of $0.15 \mathrm{mM} \mathrm{AgNO} 3$.

\section{$3.4 \quad F E-S E M$ analysis}

FE-SEM images (figure 5) of the two bacteria grown in presence of $0.15 \mathrm{mM} \mathrm{AgNO}$ showed that both the bacteria are rod shaped with presence of some particles on surface of the bacteria. Most of the particles are spherical in shape with diameter in nanometre range, i.e., 20-40 $\mathrm{nm}$. Hence, the images obtained using FE-SEM indicates the fabrication of silver nanoparticle using the extracted bacteria.

Comparison of FE-SEM results with DLS data provides us information about the variation of particle size. Generally, FE-SEM gives particular field image of the nanoparticles, however, DLS measures the hydrodynamic size of all the particles in aqueous solution, and gives average of the particles present in solution, i.e., average size of the predominant particle population. Additionally, the variation can be explained by taking the physico-chemical parameters of nanoparticles. Nanoparticles being very small in size, possess very high free energy content. Thus, when dispersed in biological solution, the nanoparticles interact with different biomolecules to release its free energy content. In presence of salts or absence of coulombs repulsive interaction, the particles self-assemble to form larger structure, hence loses the free energy content. The interaction between biomolecules and nanoparticles spontaneously form nanobio interfaces. For example, in this study, the attachment of nanoparticles on the bacteria is an example of nano-bio complex. On the other hand, assembly of nanoparticles with each other in creating larger particles, here we termed them as microparticles, as detected by DLS measurement. Additionally, we found the zeta potential value of two nanoparticle samples (AgNP1 and AgNP2) to be -16.9 and $-13.0 \mathrm{mV}$, respectively. These values of zeta potential demonstrate the incipient instability of nanoparticle solutions. Hence, the synthesized nanoparticles have the tendency to aggregate in forming the microparticles. 


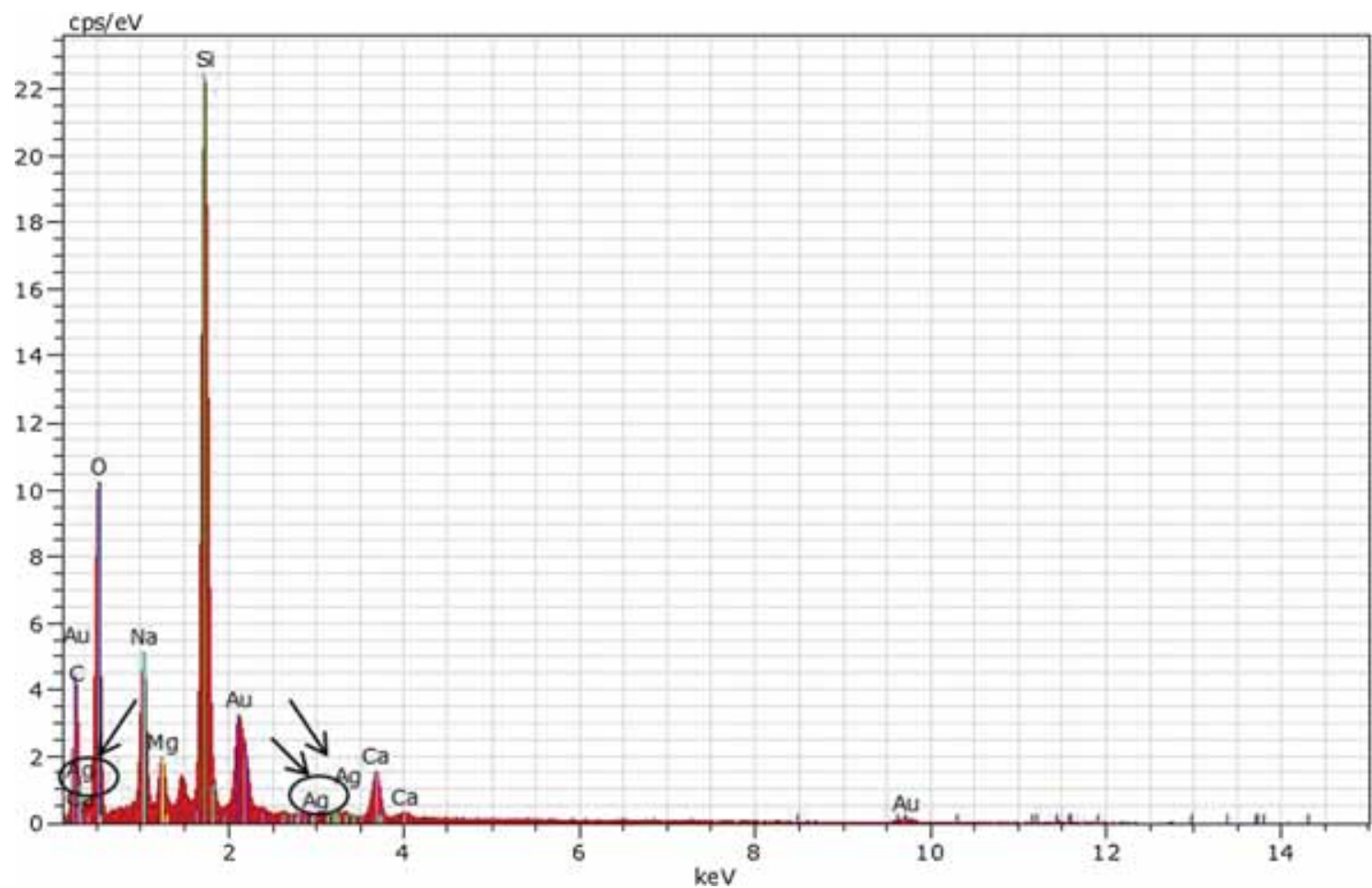

Figure 6. EDX spectra showing the presence of elemental silver on bacterial surfaces in the samples used for FE-SEM imaging.

\subsection{EDX analysis of silver nanoparticles}

EDX spectra (figure 6) showed the presence of Ag signals at bacterial surface, confirming the synthesis and secretion of silver nanoparticles. Additionally, the strong Si signal in the spectra was due to the glass slide, which was used as a platform for bacterial-nanoparticle sample preparation for analysis. The Au signal is due to the gold coating done prior to imaging. The presence of other signals in the spectra was due to the chemicals used either for preparing the sample for analysis or were integral part of the bacteria. However, the less intense signal of Ag supported our previous findings that synthesized sample contains relatively low amount of silver nanoparticles at the surface of the bacteria.

\subsection{ATR-FTIR analysis}

Figure 7 showed the bond level characterization of AgNP, fabricated using the isolated bacteria. The peaks below $800 \mathrm{~cm}^{-1}$ in the IR spectra give important information about metal-metal or metal-oxygen bonding [1]. Hence, the absorption peaks at 575 and $598 \mathrm{~cm}^{-1}$ in figure 7 represented $\mathrm{Ag}-\mathrm{O} / \mathrm{Ag}-\mathrm{Ag}$ bond vibrations, confirming the presence of AgNPs in the synthesized samples. The strong absorption peaks at 1657 and $1646 \mathrm{~cm}^{-1}$ for AgNP1 and AgNP2, respectively, are due to $\mathrm{C}=\mathrm{O}$ vibrations (amide I). On the other hand, absorbance peaks at 1530 and $1538 \mathrm{~cm}^{-1}$ for

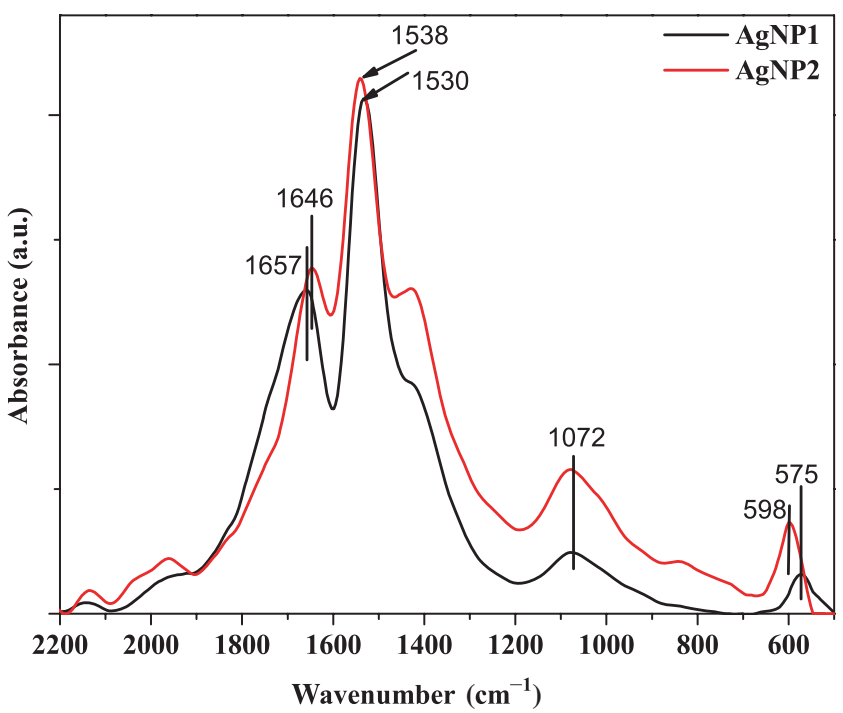

Figure 7. FT-IR spectra showing the bond level vibrations present in AgNP samples fabricated using two bacteria.

AgNP1 and AgNP2, respectively, are due to the $\mathrm{N}-\mathrm{H}$ vibrations (amide II). The peaks arising due to amide I and amide II vibrations in the spectra confirmed the presence of proteins in AgNP samples. The proteins are assumed to be responsible either for reduction of $\mathrm{AgNO}_{3}$ to silver nanoparticles or for capping of AgNP or both. In addition to that, the 
protein(s) from bacteria 1 responsible for either of the factors, is predominantly $\alpha$-helix in secondary structure contents, since $1657 \mathrm{~cm}^{-1}$ is characteristic IR absorbance peak for $\alpha$-helix. However, the proteins from bacteria 2 have predominantly $\beta$-sheet in its secondary structure contents.

The term 'green synthesis' signifies the synthesis of nanoparticles using biological entities such as: microorganisms, plants and plant products. When we are discussing about microorganisms, generally we focus on bacteria, fungi, virus, etc. However, we cannot use all microorganisms for synthesis of metal nanoparticles, and the study is a clear example of it. Initially, the work chose three bacteria for the biofabrication. One out of three bacteria, unlike other two, was sensitive to silver ion. Hence, it could not be used to produce silver nanoparticles. Our MIC results followed by nanoparticle characterization results for metalresistant bacteria strongly support that the bacteria with silver resistance have the potential to reduce the silver ion into silver nanoparticles, provided the concentration of silver ions is equal or below the $\mathrm{AgNO}_{3} \mathrm{MIC}$ against the bacteria.

It is well reported that the enzymes responsible for reduction of $\mathrm{Ag}^{+}$into $\mathrm{Ag}^{0}$ are belonged to NADPH-dependent enzyme, nitrate reductase [27]. Additionally, many studies have also shown that some of the bacterial proteins are also responsible for biosynthesis of silver nanoparticles [22,23]. However, our study (the findings from ATR-FTIR results) supports the later findings, i.e., bacterial proteins are responsible for biosynthesis of silver nanoparticles at either or both the stages. One stage involves the reduction of metal ion into elemental metal, and another stage involves capping of the elemental metal assembly at nanocrystal size [22-24]. Additionally, the microparticles formation totally depends upon the physico-chemical property of nanoparticles as discussed in DLS analysis section.

Here, fabrication of silver nanoparticle is an intracellular process and the bacterial proteins play major roles in either reduction of silver ions to elemental silver nanoparticle or capping of AgNP or both. After completion of the fabrication, the nanoparticle is secreted by exocytosis. Being small in size, these nanoparticles possess high free energy content, hence, unstable in biological milieu. As a result, the secreted nanoparticles are attached to the bacterial surface (as shown in FE-SEM image) or attached to each other forming large particles (microparticles as confirmed by DLS measurement).

In summary, the work primarily isolate the bacteria from the stressful niche, like coal mine, assuming that the bacteria isolated from stressful environment should have the potential to withstand significant concentration of antimicrobial metal ions like $\operatorname{Ag}(\mathrm{I})$. Hence, the isolated bacteria shall be suitable candidate for respective metal nanoparticle fabrication. Here, first the work evaluated the MIC value of $\mathrm{AgNO}_{3}$ against isolated bacteria, and synthesized silver nanoparticles just below the MIC that kept the bacteria live, while $\operatorname{Ag}(\mathrm{I})$ ion is being reduced to $\operatorname{Ag}(0)$ element. Unlike other works [22,23] where scientific groups have taken bacterial mass for metal ion reduction, we have shown the possibility of using the live bacteria for the same purpose, which is a novel endeavour in the field of material sciences, and opens the avenue for green continuous fabrication of nanomaterials.

\section{Conclusion}

The findings from the experimental work suggest that the bacteria isolated from the coal mines have the potential to resist relatively higher concentration of silver ions, hence can be used as potential biological agents for reduction of metal ions into elemental nano- or micro-particles. Initially, the reduction of nano-/micro-particles using these bacteria were confirmed from the UV-Vis spectroscope, DLS, zeta and EDX analyses, whereas FE-SEM analysis revealed the spherical-shaped nanoparticle attached on surface of the bacteria. Additionally, as suggested by ATR-FTIR spectra, the proteins in the bacterial cells are found to be the principal agent for the reduction of silver ions to different size particles. As a conclusion, the bacteria found in the coal mine are suitable agents for synthesis of silver nano-/micro-particles.

\section{Acknowledgements}

We are thankful to the Department of Ceramic Engineering, National Institute of Technology, Rourkela, Odisha, India, for providing us FE-SEM facility for fulfilling the objective of the research work. For the financial support, we would like to acknowledge Department of Science and Technology and Ministry of Human Resource and Development, Govt. of India, India.

\section{References}

[1] Arakha M, Saleem M, Mallick B C and Jha S 2015 Scientific Rep. 5 doi: 10.1038/srep09578

[2] Vijayaraghavan K, Nalini S K, Prakash N U and Madhankumar D 2012 Colloids Surfaces B: Biointerfaces 94114

[3] Arakha M et al 2015 Scientific Rep. 5 doi: 10.1038/ srep 14813

[4] Gleiter H 2000 Acta Mater. 481

[5] Królikowska A, Kudelski A, Michota A and Bukowska J 2003 Surf. Sci. 532227

[6] Kumar A et al 2003 Langmuir 196277

[7] Chandrasekharan N and Kamat P V 2000 J. Phys. Chem. B 10410851

[8] Peto G et al 2002 Mater. Sci. Eng. C: Biomim. Supramolec. Syst. 1995

[9] Schaadt D M, Feng B and Yu E T 2005 Appl. Phys. Lett. 86 063106

[10] Gubin S P 2009 Magnetic nanoparticles. (John Wiley \& Sons)

[11] Jain P K, Huang X, El-Sayed I H and El-Sayed M A 2007 Plasmonics 2107 
[12] Behera S, Jha S, Arakha M and Panigrahi T 2013 Inter. J. Eng. Res. Appl. 3058

[13] Mohanta Y K and Behera S K 2014 Bioprocess Biosyst. Eng. 372263

[14] Li X, Xu H, Chen Z-S and Chen G 2011 J. Nanomater. 201116

[15] Iravani S 2014 Inter. Scholar. Res. Notices. 2014 doi: $10.1155 / 2014 / 359316$

[16] Silver S 1996 Gene 1799

[17] Beveridge T J et al 1996 Adv. Microb. Phys. 38177

[18] Lee H J, Yeo S Y and Jeong S H 2003 J. Mater. Sci. 382199

[19] Morones J R et al 2005 Nanotechnology 162346

[20] Johnson D B 2003 Water Air Soil Pollut.: Focus 347
[21] Castro-Silva M A et al 2003 Brazilian J. Microbiol. 34 45

[22] Fayaz A M et al 2010 Nanomed.: Nanotechnol. Biol. Med. 6 103

[23] Chowdhury S, Basu A and Kundu S 2014 Nanoscale Res. Lett. 91

[24] Ramanathan R et al 2013 Nanoscale 52300

[25] Bar H et al 2009 Colloids Surf. A: Physicochem. Eng. Aspects 339134

[26] Mohan S et al 2014 Carbohydr. Polym. 106469

[27] Sadowski Z 2010 doi: 10.5772/8508 